\section{Influência do uso de cinza volante na elevação adiabática de temperatura e resistência à compressão de concretos}

\author{
Influence of the use of fly ash on the \\ adiabatic heat evolution and \\ compressive strength of \\ concretes
}

${ }^{1}$ Universidade Federal de Santa Catarina, UFSC, Santa Catarina, Florianópolis, Brasil.
e-mail: paulorm.matos@gmail.com, ricardo.junckes@bol.com.br, prudenciouk@ hotmail.com

\title{
RESUMO
}

A construção de grandes edifícios tem requerido a execução de blocos de fundação de grandes dimensões, com volumes que chegam a milhares de $\mathrm{m}^{3}$ de concreto. Em geral, estas estruturas são executadas em concretos autoadensáveis e/ou de altas resistências, resultando em elevados consumos de aglomerante. Nesses casos, o emprego de cinza volante em substituição ao cimento Portland é uma alternativa bastante difundida, tanto para a redução do calor de hidratação quanto para a mitigação da formação da etringita tardia. Contudo, os elevados consumos de aglomerante geralmente empregados em tais concretos resultam em altas temperaturas, pondo em dúvida a eficácia desta adição mineral para a redução do calor liberado. Desta forma, o presente trabalho tem como objetivo avaliar simultaneamente o efeito da substituição do cimento Portland por cinza volante na

elevação adiabática de temperatura e na resistência à compressão de concretos. Para isso, foram produzidos concretos com três classes de resistência à compressão $(35,45$ e $55 \mathrm{MPa})$ e quatro teores de substituição do cimento por cinza volante $(0,15,30$ e $45 \%)$. A elevação de temperatura das misturas foi monitorada por um calorímetro adiabático, durante 72 horas. Aos 28 dias, foram determinadas as resistências à compressão de corpos de prova curados no regime adiabático e à temperatura ambiente. Ainda, foram confeccionadas pastas de cimento com as mesmas relações água/aglomerante e teores de substituição de cimento dos concretos, sumbetidas à análise termogravimétrica (TGA) aos 28 dias. Os resultados mostraram que, independente da classe de resistência ou do teor de substituição da cinza volante, os coeficientes de elevação adiabática (correspondente à variação de temperatura dividida pelo consumo de aglomerante $/ \mathrm{m}^{3}$ de concreto) foram bastante semelhantes. O regime adiabático promoveu uma redução na resistência à compressão aos 28 dias, na ordem de $10 \%$ em comparação à cura à temperatura ambiente. Por fim, a atividade pozolânica da cinza volante foi confirmada pela TGA. Diante dos resultados, pode-se concluir que o emprego de cinza volante em grandes massas de concreto com elevados consumos de aglomerante torna-se uma alternativa pouco eficiente para a redução da liberação de calor. Contudo, seu uso é indicado devido aos benefícios na resistência à compressão e na prevenção da formação de etringita tardia.

Palavras-chave: Cinza volante, elevação de temperatura, calorimetria adiabática, concreto massa.

\section{ABSTRACT}

The construction of high buildings has required the execution of pile caps that reach thousands of $\mathrm{m}^{3}$ of concrete. In general, these structures are built using self-compacting and/or high compressive strength concretes, resulting in high binder contents. In these cases, the use of fly ash replacing Portland cement is a well-known alternative, both for the reduction of hydration heat and for the mitigation of delayed ettringite formation. However, the high binder contents generally used in such concretes results in high temperatures, 
creating an uncertainty about the efficacy of this mineral admixture for the reduction of the hydration heat. Thus, the current work aims to evaluate the effect of the replacement of Portland cement by fly ash in the adiabatic elevation of temperature and in the compressive strength of concretes. In this regard, concretes were produced with three classes of compressive strength $(35,45$ and $55 \mathrm{MPa})$ and four cement replacement ratios by fly ash $(0,15,30$ and $45 \%)$. The temperature elevation of the concretes was monitored by an adiabatic calorimeter for 72 hours. At 28 days, the compressive strength of specimens cured in the adiabatic condition and at room temperature were determined. Finally, the pozzolanic activity of fly ash was evaluated by thermogravimetric analysis (TGA). It was found that, regardless of the resistance class or the replacement content of fly ash, the adiabatic elevation coefficients (corresponding to the temperature variation divided by the consumption of binder $/ \mathrm{m}^{3}$ of concrete) were quite similar. The adiabatic condition promoted a reduction in compressive strength at 28 days, on the order of $10 \%$ compared to curing at room temperature. Also, the pozzolanic activity of fly ash was confirmed by TGA. Considering the results, it can be concluded that the use of fly ash in large masses of concrete with high binder contents becomes an inefficient alternative for the reduction of the heat release. However, its use is indicated because of the benefits in compressive strength and prevention of delayed ettringite formation.

Keywords: Fly ash; temperature elevation; adiabatic calorimetry; mass concrete.

\section{INTRODUÇÃO}

A construção de edifícios cada vez mais altos é acompanhada pela necessidade de grandes blocos de fundação. Na cidade de Balneário Camboriú - SC, por exemplo, tornou-se comum a execução de blocos de fundação de milhares de $\mathrm{m}^{3}$ de concreto, chegando a $5300 \mathrm{~m}^{3}$ no edifício Infinity Coast, em 2014 . Em geral, estas estruturas são executadas em concretos autoadensáveis e/ou de altas resistências, resultando em elevados consumos de aglomerante. Assim, tais estruturas podem apresentar elevações de temperatura excessivas, que podem ocasionar efeitos deletérios nas mesmas [1], [2].

A fissuração de origem térmica é um problema diretamente relacionado à elevação e distribuição da temperatura nas peças de concreto [1]. O calor gerado pela hidratação do cimento é transferido do núcleo para as superfícies, de onde é dissipado para o ambiente. A presença de gradientes de temperatura gera tensões de tração e compressão no concreto, as quais podem ocasionar a fissuração do mesmo [3]. Outro processo danoso causado pela elevação de temperatura do concreto é a formação de etringita tardia: em concretos submetidos a temperaturas superiores a $70{ }^{\circ} \mathrm{C}$, pode ocorrer decomposição da etringita e posterior recristalização da mesma na matriz cimentícia endurecida, resultando na expansão da pasta e fissuração do concreto [2].

A elevação de temperatura na execução de grandes estruturas de concreto armado é uma preocupação antiga. Em 1935, na construção da Barragem de Hoover (Estados Unidos), já foram adotados cuidados em relação a este problema, tais como o uso de cimento com baixo calor de hidratação e um sistema de pósresfriamento da estrutura. O uso da cinza volante para a redução do calor de hidratação dos concretos é bastante difundido [4]-[6]. A temperaturas ambiente, a reação da cinza é lenta e só se dá alguns dias após o início da hidratação do cimento [7], sendo supostamente ideal para este fim. No entanto, em grandes massas de concreto com resistências à compressão elevadas, os grandes consumos de aglomerante utilizados podem levar a estruturas a altas temperaturas, podendo chegar a cerca de $80{ }^{\circ} \mathrm{C}$ [8]. Ainda, a baixa condutividade térmica do material torna estas grandes massas de concreto sistemas praticamente adiabáticos [9]-[11]. Estas condições podem antecipar as reações pozolânicas da cinza volante, resultando em uma precoce liberação de calor por tais reações [12], não contribuindo para a redução da elevação de temperatura do concreto.

Diversos autores observaram aumentos significativos na taxa de reação pozolânica de cinzas volantes com o aumento da temperatura. Deschner et al. [13] avaliaram a hidratação de pastas contendo 50\% de substituição do cimento por cinza volante, com temperaturas de cura variando de 7 a $80^{\circ} \mathrm{C}$. $\mathrm{O}$ incremento de temperatura de 7 para $23^{\circ} \mathrm{C}$ antecipou o início da reação da cinza volante de 90 para 7 dias, e para 1 dia aos 50 ${ }^{\circ} \mathrm{C}$. Os efeitos típicos da reação pozolânica na hidratação, tais como o consumo de $\mathrm{Ca}(\mathrm{OH})_{2}$, a liberação de íons $\mathrm{Al}$ e Si na solução de poros e a formação adicional de C-S-H, foram acelerados em elevadas temperaturas. Resultados semelhantes foram encontrados por Narmluk e Nawa [14], que avaliaram a hidratação de pastas contendo 25 e $50 \%$ de substituição do cimento Portland por cinza volante, curadas a 25,35 e $50^{\circ} \mathrm{C}$. Ainda, Kumar et al. [15] e Han et al. [16] estudaram a evolução do calor de hidratação de cimentos contendo diferentes teores de cinza volante $(0-65 \%)$ por meio de calorimetria isotérmica à diferentes temperaturas $\left(25-60^{\circ} \mathrm{C}\right)$. Ambos observaram que o aumento da temperatura promoveu uma grande ativação da cinza volante, especialmente aos $60^{\circ} \mathrm{C}$. Dessa forma, o emprego de cinza volante em grandes massas de concreto pode torná-la pouco eficiente para a redução da liberação de calor.

Em contrapartida, a substituição do cimento Portland por cinza volante pode influenciar na resistência à compressão, além da melhoria na durabilidade do material [7]. No geral, substituições de até $15 \%$ mostramse eficientes na melhora da resistência aos 28 dias. Já teores maiores $(30-40 \%)$ promovem ganhos de resis- 
tência em idades superiores (> 90 dias), podendo, contudo, reduzir a resistência aos 28 dias [17], [18]. Esta influência no comportamento mecânico possibilitaria, em certos casos, a redução do consumo de aglomerante para atingir uma dada resistência, reduzindo assim o calor liberado.

Sendo assim, o presente trabalho tem como objetivo avaliar simultaneamente o efeito da substituição do cimento Portland por cinza volante na elevação adiabática de temperatura e na resistência à compressão de concretos de diferentes classes de resistência à compressão, contendo diferentes teores de cinza volante.

\section{MATERIAIS E MÉTODOS}

A seguir, será apresentada a caracterização dos materiais empregados no presente trabalho (cimento, cinza volante, agregados e aditivo), o procedimento de preparação das amostras e a descrição dos procedimentos experimentais adotados.

\subsection{Materiais}

Um cimento classificado como CPV-ARI pela ABNT NBR 5733 [19] foi empregado em todas as misturas. As características físicas e químicas do mesmo estão apresentadas na Tabela 1. Foi utilizada uma cinza volante proveniente de Candiota - RS. A mesma foi caracterizada por meio de difratometria de raios X (modelo Miniflex II Desktop X-Ray Difractometer - Rigaku, com radiação Cu / 30 kV / 15 mA, comprimento de onda $\lambda=1,5406 \AA$, amplitude de escaneamento de 3 a $90^{\circ}$ e passo de $0,05^{\circ}$ /segundo). O difratograma está apresentado na Figura 1, no qual foi indicada a existência de um halo amorfo, conforme indicam Hoppe Filho et al. [20]. A atividade pozolânica da mesma foi caracterizada através do método Chapelle modificado, conforme prescreve a ABNT NBR 15895 [21], apresentando um consumo de 488,0 $\mathrm{mg} \mathrm{de} \mathrm{Ca}(\mathrm{OH})_{2} / \mathrm{g}$ de cinza volante. A composição química da cinza volante, bem como as características físicas da mesma estão apresentadas na Tabela 1. A Figura 2 apresenta as distribuições do tamanho de partículas do cimento e da cinza volante, obtidas através do Analisador de Tamanho de Partículas Microtrac S3500 (granulômetro a laser, por via seca).

Tabela 1: Características químicas e físicas do cimento Portland e da cinza volante empregada.

\begin{tabular}{|c|c|c|}
\hline Compostos & Cimento & Cinza volante \\
\hline \multicolumn{3}{|c|}{ Características químicas (\%) } \\
\hline $\mathrm{SiO}_{2}$ & 18,69 & 69,30 \\
\hline $\mathrm{Al}_{2} \mathrm{O}_{3}$ & 4,25 & 18,90 \\
\hline $\mathrm{Fe}_{2} \mathrm{O}_{3}$ & 2,96 & 6,20 \\
\hline $\mathrm{CaO}$ & 60,12 & 1,10 \\
\hline $\mathrm{K}_{2} \mathrm{O}$ & \multirow{2}{*}{$0,67 *$} & \multirow{2}{*}{$1,47 *$} \\
\hline $\mathrm{Na}_{2} \mathrm{O}$ & & \\
\hline $\mathrm{MgO}$ & 4,08 & 1,00 \\
\hline $\mathrm{SO}_{3}$ & 3,23 & 0,18 \\
\hline P.F & 3,24 & 1,20 \\
\hline R.I. & 0,7 & - \\
\hline $\mathrm{CaO}$ Livre & 0,59 & - \\
\hline \multicolumn{3}{|c|}{ Características físicas } \\
\hline M.E. $\left(\mathrm{g} / \mathrm{cm}^{3}\right)$ & 3,12 & 2,40 \\
\hline Blaine $\left(\mathrm{m}^{2} / \mathrm{kg}\right)$ & 447,4 & - \\
\hline D50 $(\mu \mathrm{m})$ & 15,19 & 58,28 \\
\hline * Álcalis equ & $\begin{array}{l}\text { s; } P F=\text { per } \\
\text { luo insolúve }\end{array}$ & fogo; RI = resí- \\
\hline
\end{tabular}




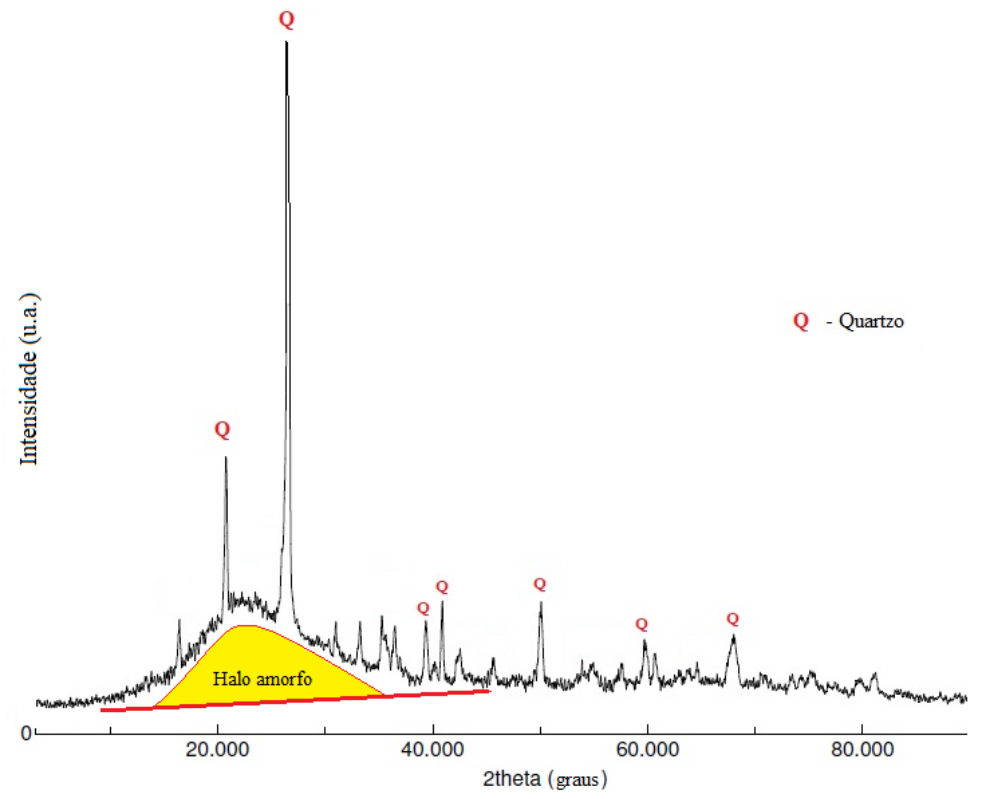

Figura 1: Difratograma da cinza volante empregada.

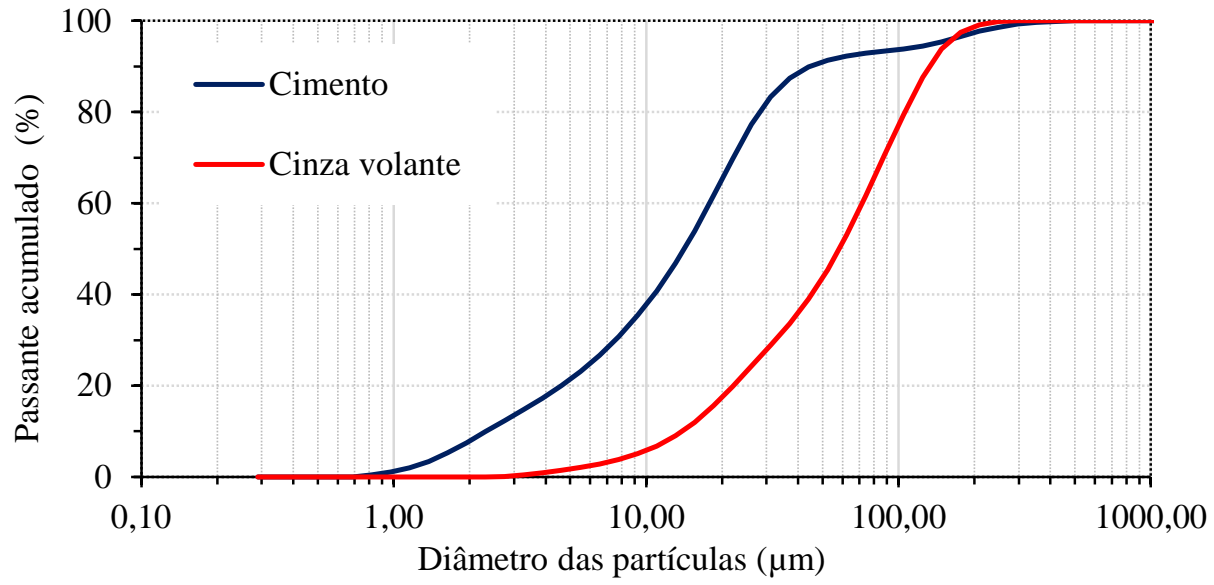

Figura 2: Distribuição do tamanho de partículas do cimento Portland e da cinza volante.

Como agregados miúdos, foi empregada uma areia natural com módulo de finura 1,42 e massa específica 2,64 g/ $\mathrm{cm}^{3}$, e uma areia de britagem granítica com módulo de finura 2,78 e massa específica $2,78 \mathrm{~g} / \mathrm{cm}^{3}$. As areias foram utilizadas na proporção $70 \%$ areia natural $+30 \%$ areia de britagem, por se tratar de uma combinação convencionalmente empregada pelas concreteiras da região para estes materiais. As distribuições granulométricas das duas areias estão apresentadas na Figura 3. Foram utilizados dois tipos de agregados graúdos: um com zona granulométrica 4,75/9,5 mm e massa específica $2,62 \mathrm{~g} / \mathrm{cm}^{3}$, e outro com zona granulométrica 9,5/25 mm e massa específica $2,64 \mathrm{~g} / \mathrm{cm}^{3}$, ambos de origem granítica. A distribuição granulométrica dos mesmos é apresentada na Figura 3. 


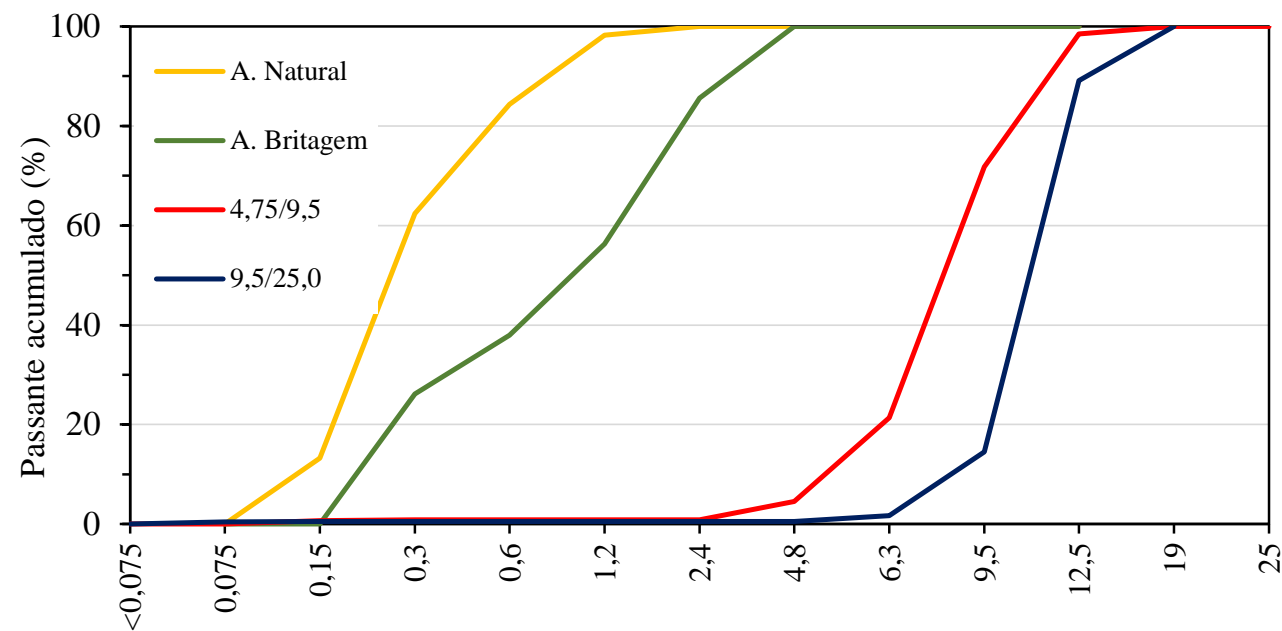

Abertura da peneira (mm)

Figura 3: Distribuição granulométrica dos agregados.

Na preparação dos concretos, foi utilizado um aditivo plastificante à base de lignosulfonato e naftaleno sulfonato. Segundo o fabricante, o aditivo possui densidade de $1,21 \mathrm{~g} / \mathrm{cm}^{3}$, teor de sólidos de $32,8 \%$ e $\mathrm{pH}$ 8,0 .

\subsection{Proporcionamento das misturas}

Um estudo preliminar foi realizado para a determinação das composições das misturas [22]. Para cada teor de substituição, foram confeccionados 3 concretos para a determinação de uma curva de dosagem (metodologia IPT/EPUSP). A partir de tais curvas, foram determinadas as composições dos concretos para as resistências características desejadas.

A Tabela 2 apresenta a composição das misturas confeccionadas. A nomenclatura das misturas é composta pela resistência característica do concreto (FC35, FC45 e FC55 para 35, 45 e 55 MPa, respectivamente), seguido pelo teor de substituição volumétrica do cimento por cinza volante (CV0, CV15, CV30 e CV45 para $0,15,30$ e $45 \%$, respectivamente).

Tabela 2: Proporcionamento das composições dos concretos $\left(\mathrm{kg} / \mathrm{m}^{3}\right)$.

\begin{tabular}{l|c|c|c|c|c|c|c}
\hline Mistura & Cimento & Cinza & Areia & Brita & Água & Plastificante & a/c \\
\hline FC35 - CV0 & 263 & - & 914 & 1043 & 171 & 3,10 & 0,65 \\
\hline FC35 - CV15 & 271 & 48 & 847 & 1044 & 172 & 2,58 & 0,54 \\
\hline FC35 - CV30 & 239 & 102 & 788 & 1024 & 167 & 3,28 & 0,49 \\
\hline FC35 - CV45 & 217 & 178 & 705 & 1017 & 158 & 3,36 & 0,40 \\
\hline FC45 - CV0 & 355 & - & 823 & 1044 & 174 & 2,59 & 0,49 \\
\hline FC45 - CV15 & 332 & 59 & 777 & 1048 & 184 & 4,30 & 0,47 \\
\hline FC45 - CV30 & 291 & 125 & 703 & 1019 & 178 & 4,40 & 0,43 \\
\hline FC45 - CV45 & 277 & 227 & 589 & 1021 & 172 & 5,50 & 0,34 \\
\hline FC55 - CV0 & 499 & - & 681 & 1047 & 185 & 5,39 & 0,37 \\
\hline FC55 - CV15 & 407 & 72 & 690 & 1052 & 177 & 5,27 & 0,37 \\
\hline FC55 - CV30 & 353 & 151 & 599 & 1013 & 182 & 5,81 & 0,36 \\
\hline FC55 - CV45 & 359 & 293 & 431 & 1028 & 183 & 7,57 & 0,28 \\
\hline
\end{tabular}

\subsection{Preparação das amostras}

Os concretos foram preparados em um misturador de eixo inclinado, em lotes de 20 litros. Os materiais foram adicionados ao misturador na seguinte sequência: agregado graúdo $+70 \%$ da água, aglomerante, agregado miúdo, aditivo plastificante, restante da água. Após cada adição, os materiais foram misturados por cerca 
de 2 minuto até homogeneização. O tempo total de mistura de cada amostra foi de aproximadamente 10 minutos. A quantidade de aditivo plastificante foi ajustada para cada mistura, a fim de obter uma consistência de 100 - 160 mm (Classe S100, ABNT NBT 7212 [23]).

\subsection{Ensaios}

A elevação de temperatura dos concretos foi avaliada através de um calorímetro adiabático (Figura 4), desenvolvido pelo grupo GTec-UFSC [22]. O equipamento é composto por um tanque metálico preenchido com água e um sistema de monitoramento de temperatura e aquecimento de água automatizado, ilustrado esquematicamente na Figura 5. Uma amostra de 4 litros de concreto é adicionada à um recipiente metálico e emergida no tanque. $\mathrm{O}$ sistema monitora continuamente a temperatura da amostra, mantendo a temperatura da água que a circunda igual à da mesma. O tanque é equipado com quatro resistências de 5200 watts cada. A precisão do sistema é de $1,0^{\circ} \mathrm{C}$.

Os dados de temperatura dos concretos foram registrados por meio de um aquisitor Datalogger Agilent 34970A, equipado com termopares tipo K. As temperaturas foram registradas em intervalos de 15 minutos durante 72 horas (período suficiente para estabilizar a elevação de temperatura).

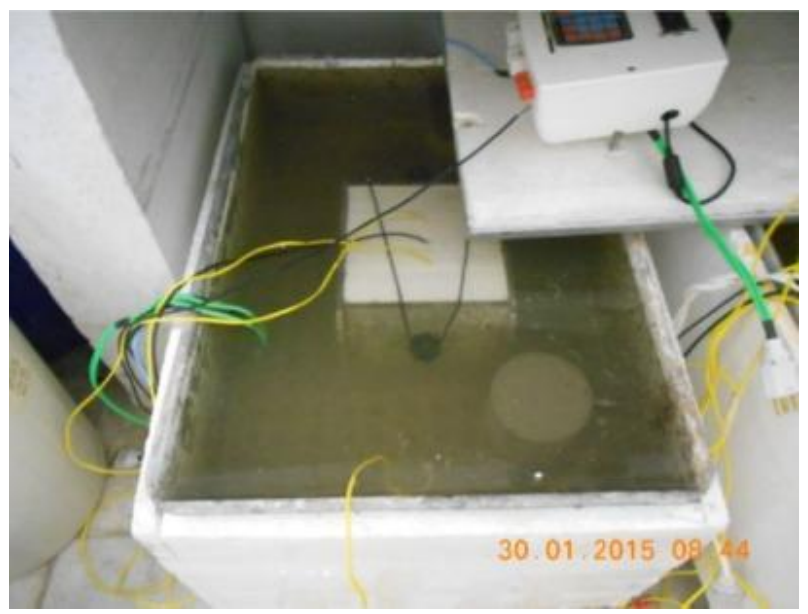

Figura 4: Calorímetro adiabático.

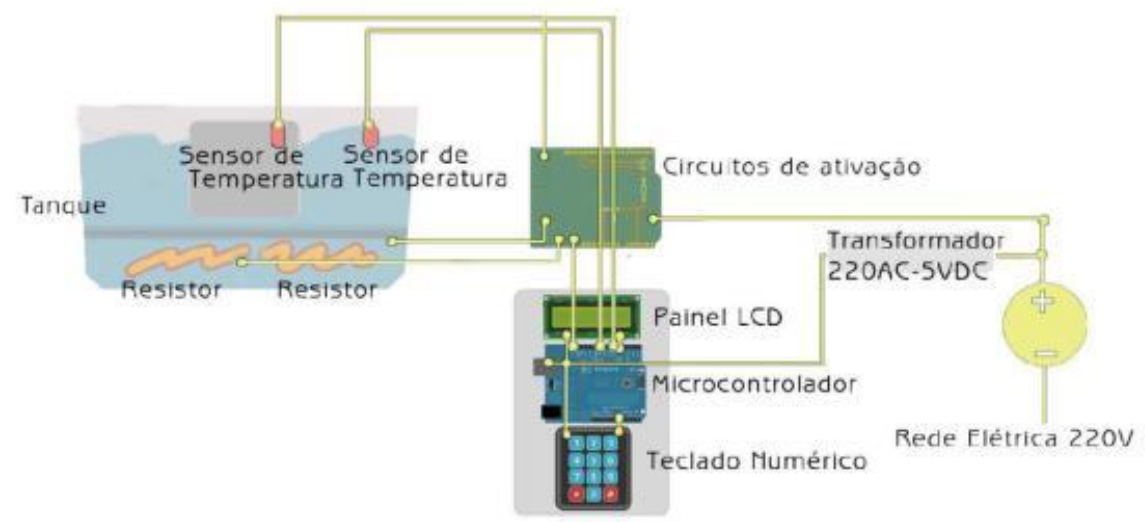

Figura 5: Ilustração esquemática da montagem do calorímetro adiabático.

Para a determinação da resistência à compressão dos concretos, foram moldados 4 corpos de prova cilíndricos de $(10 \times 20) \mathrm{cm}$ para cada mistura. Dois corpos de prova foram mantidos em sala climatizada $(23 \pm 2$ ${ }^{\circ} \mathrm{C}$ ) por $24 \mathrm{~h}$, desmoldados e mantidos em câmara úmida até a idade de ruptura. Os outros dois corpos de prova foram imersos no tanque do calorímetro por $72 \mathrm{~h}$, posteriormente sendo desmoldados e mantidos em câmara úmida até a idade de ruptura. O segundo regime de cura foi adotado com o intuito de verificar o efeito da cura adiabática na resistência à compressão dos concretos. Todos os corpos de prova foram ensaiados à compressão aos 28 dias.

Por fim, a atividade pozolânica da cinza foi avaliada por meio de termogravimetria. Para isso, foram confeccionadas pastas de cimento com as mesmas relações água/aglomerante e teores de substituição de ci- 
mento dos concretos. As amostras foram misturadas manualmente por 2 minutos, devidamente seladas e armazenadas à $(23 \pm 2)^{\circ} \mathrm{C}$. Após 28 dias, a hidratação das pastas foi interrompida por meio de liofilização (imersão das amostras em nitrogênio líquido por $24 \mathrm{~h}$, seguido da aplicação de vácuo por $24 \mathrm{~h}$ ). As amostras foram mantidas em dessecador até a realização do ensaio. A termogravimetria foi realizada em um analisador DTG-60 (Shimadzu), com taxa de aquecimento de $10^{\circ} \mathrm{C} / \mathrm{min}$ até $900{ }^{\circ} \mathrm{C}$ e vazão de $100 \mathrm{ml} / \mathrm{min}$ de $\mathrm{N}_{2}$.

\section{RESULTADOS E DISCUSSÕES}

Nesta seção, serão apresentados os resultados obtidos no programa experimental proposto, acompanhados das devidas discussões. Por fim, será feita uma breve discussão sobre a eficácia da cinza volante para uso em grandes massas de concreto.

\subsection{Calorimetria adiabática}

As curvas de elevação de temperatura dos concretos estão apresentadas nas Figuras 6 a 8 . As temperaturas foram monitoradas durante 72 horas, com exceção da mistura FC55 - CV45, a qual foi monitorada por 84 horas. Tal mistura apresentou um retardo excessivo no início da elevação de temperatura, provavelmente ocasionado pelo elevado teor de aditivo plastificante empregado (cerca de 1,2\% da massa de aglomerante, acima da dosagem máxima de 1,0\% recomendada pelo fabricante). Dessa forma, a curva de elevação de temperatura da mistura FC55 - CV45 teve suas primeiras 12 horas omitidas.

Pode-se observar uma forte influência da classe de resistência (e consequentemente do consumo de aglomerante) na elevação de temperatura dos concretos: as médias das temperaturas máximas das misturas FC35, FC45 e FC55 foram respectivamente $67,9,76,1$ e $84,5{ }^{\circ} \mathrm{C}$. A mistura FC45 - CV45, por sua vez, apresentou uma temperatura máxima de $89,9^{\circ} \mathrm{C}$, muito acima das demais misturas da mesma classe de resistência. Isso provavelmente ocorreu devido ao seu elevado consumo de aglomerante, que foi de 504 $\mathrm{kg} / \mathrm{m}^{3}$, enquanto os consumos das demais misturas desta classe de resistência foram de 355 a $415 \mathrm{~kg} / \mathrm{m}^{3}$. De fato, a temperatura máxima da mistura FC45 - CV45 é semelhante às atingidas pelas misturas FC55, que apresentam consumos de aglomerante de 479 a $652 \mathrm{~kg} / \mathrm{m}^{3}$.

O aumento do teor de substituição do cimento pela cinza volante retardou o início da elevação de temperatura, independente da classe de resistência. Resultados semelhantes foram relatados por outros autores [24]-[27]. Segundo Nicoleau et al. [28], este retardo se dá devido ao aumento da concentração de íons Al na solução de poros. Tais íons, liberados pela cinza volante, inibem a hidratação da alita nas primeiras horas. Este fato também é constatado por Scholer et al. [29]. A mistura FC45 - CV45, por sua vez, foi uma exceção a esse comportamento, tendo o início da liberação de calor antes da mistura FC45 - CV30 (Figura 7). O consumo de aglomerante da mistura FC45 - CV45, muito superior ao demais misturas da mesma classe de resistência, provavelmente antecipou o início da elevação de temperatura, mesmo com um alto teor de substituição do cimento. Corroborando com esta hipótese, é possível notar a semelhança das curvas de elevação de temperatura das misturas FC45 - CV45 (Figura 7) e FC55 - CV30 (Figura 8), as quais apresentam consumos de aglomerante de aproximadamente $505 \mathrm{~kg} / \mathrm{m}^{3}$ : ambas têm o início da elevação de temperatura em cerca de 28 horas e variações de temperatura semelhantes $\left(60,2{ }^{\circ} \mathrm{C}\right.$ para $\mathrm{FC} 45$ - CV45 e 57,3 ${ }^{\circ} \mathrm{C}$ para FC55 - CV30). 


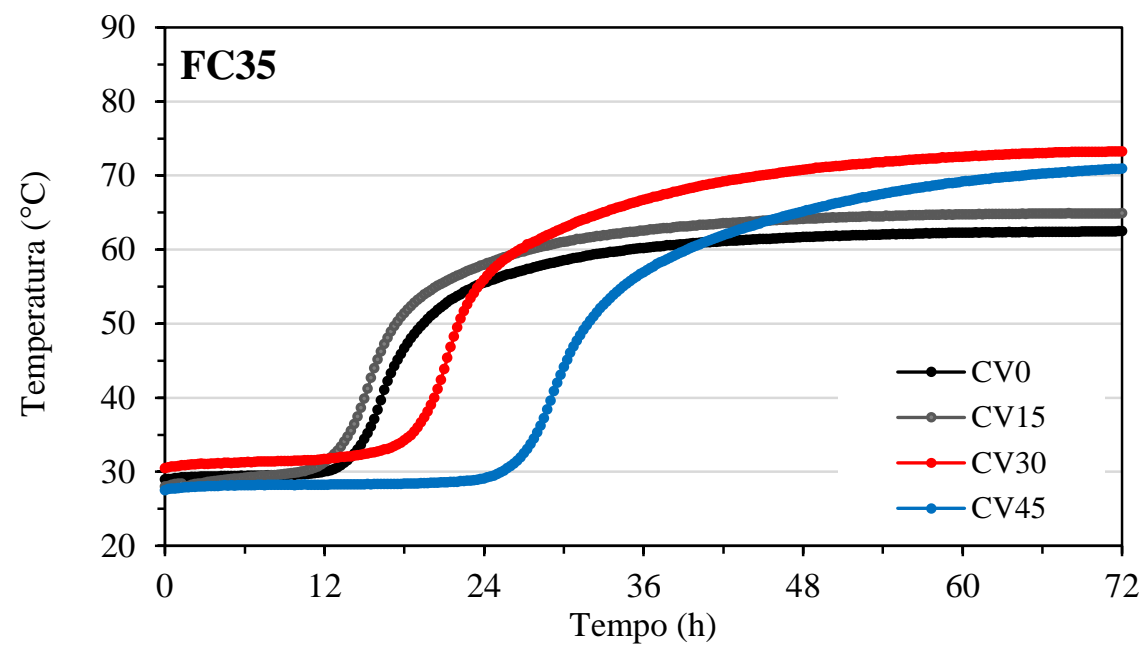

Figura 6: Curvas de elevação de temperatura das misturas FC35.

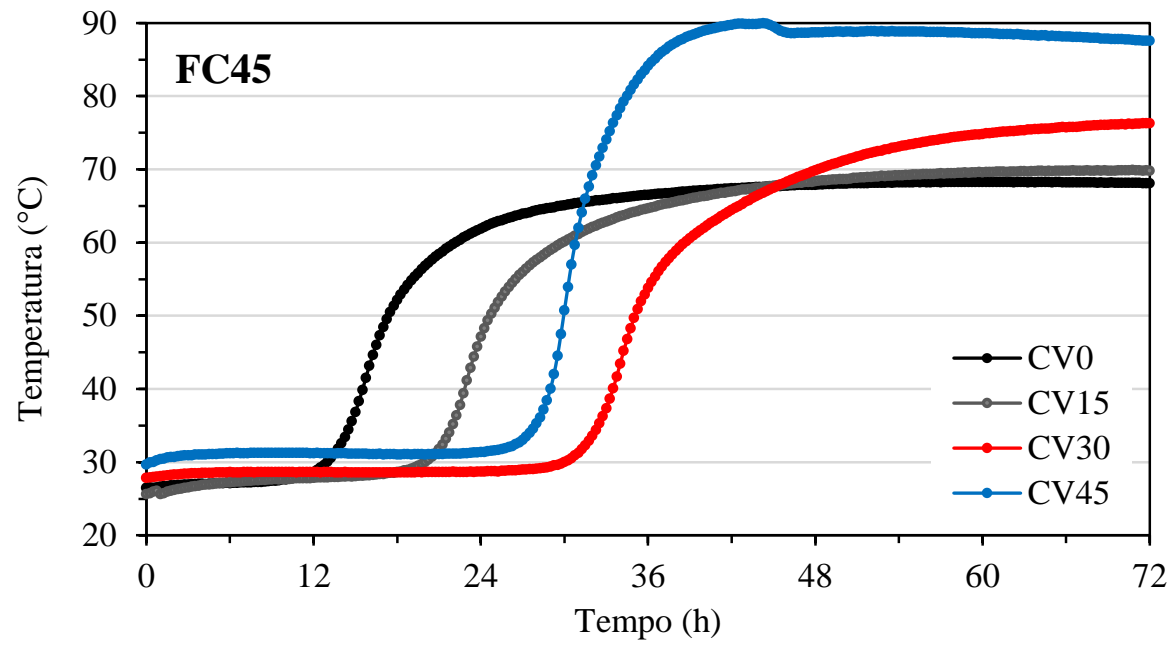

Figura 7: Curvas de elevação de temperatura das misturas FC45.

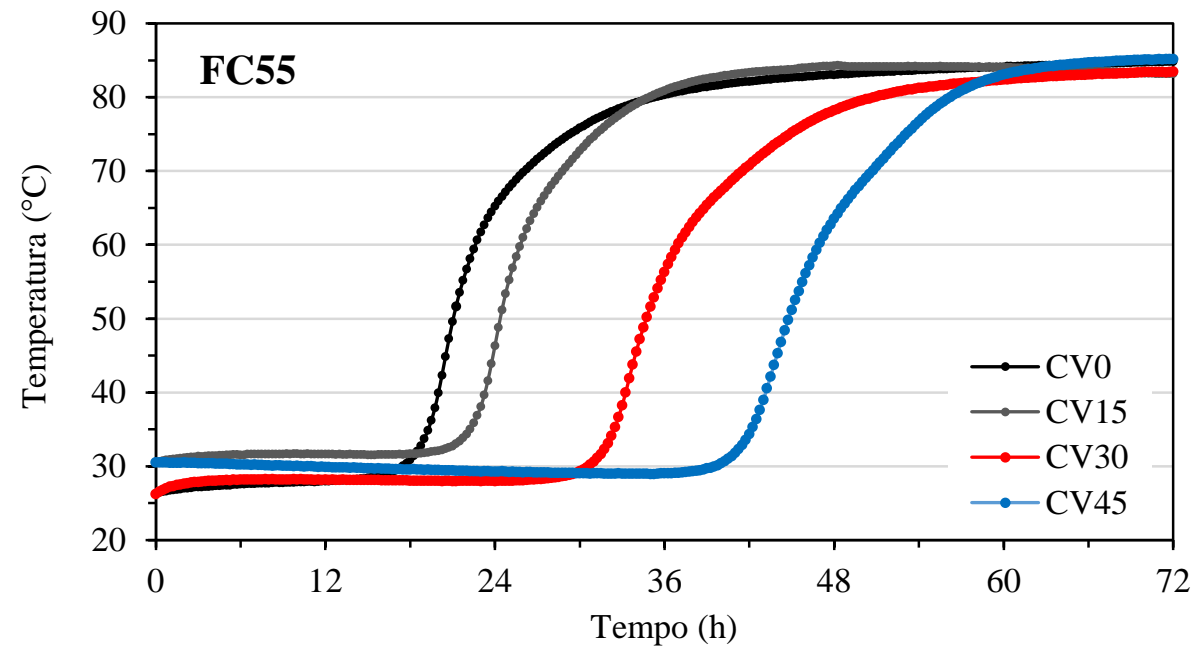

Figura 8: Curvas de elevação de temperatura das misturas FC55.

As variações de temperatura dos concretos durante o ensaio são apresentadas na Tabela 3. Para cada mistura, foi determinado o coeficiente de elevação adiabática, o qual corresponde à variação de temperatura dividida pelo consumo de aglomerante $/ \mathrm{m}^{3}$ de concreto, expresso em ${ }^{\circ} \mathrm{C} . \mathrm{m}^{3} / \mathrm{kg}$. Nota-se que, independente da 
classe de resistência ou do teor de substituição dos concretos, os coeficientes de elevação adiabática foram bastante semelhantes (com exceção da mistura FC55 - CV45): de 0,110 a 0,128 ${ }^{\circ} \mathrm{C} \cdot \mathrm{m}^{3} / \mathrm{kg}$. O desvio padrão de $0,005{ }^{\circ} \mathrm{C} \cdot \mathrm{m}^{3} / \mathrm{kg}$ demonstra a baixa variabilidade entre os valores. Coeficientes semelhantes são relatados por diferentes autores [30]-[32].

Tabela 3: Elevação de temperatura dos concretos.

\begin{tabular}{l|c|c|c|c|c}
\hline Mistura & $\begin{array}{c}\text { Aglomerante } \\
\left(\mathbf{k g} / \mathbf{m}^{3}\right)\end{array}$ & $\mathbf{T}$ inicial $\left({ }^{\circ} \mathbf{C}\right)$ & T final $\left({ }^{\circ} \mathbf{C}\right)$ & Variação $\left({ }^{\circ} \mathbf{C}\right)$ & ${ }^{\circ} \mathbf{C} . \mathbf{m}^{3} / \mathbf{k g}$ \\
\hline FC35 - CV0 & 262,6 & 29,0 & 62,5 & 33,5 & 0,128 \\
\hline FC35 - CV15 & 319,0 & 27,9 & 64,9 & 37,1 & 0,116 \\
\hline FC35 - CV30 & 341,2 & 30,5 & 73,3 & 42,8 & 0,125 \\
\hline FC35 - CV45 & 395,5 & 27,5 & 70,9 & 43,4 & 0,110 \\
\hline FC45 - CV0 & 354,9 & 26,5 & 68,3 & 41,8 & 0,118 \\
\hline FC45 - CV15 & 390,5 & 25,6 & 69,9 & 44,3 & 0,113 \\
\hline FC45 - CV30 & 415,0 & 27,8 & 76,3 & 48,5 & 0,117 \\
\hline FC45 - CV45 & 504,4 & 29,7 & 89,9 & 60,2 & 0,120 \\
\hline FC55 - CV0 & 499,2 & 26,3 & 84,6 & 58,3 & 0,117 \\
\hline FC55 - CV15 & 478,7 & 30,6 & 84,3 & 53,8 & 0,112 \\
\hline FC55 - CV30 & 504,9 & 26,2 & 83,5 & 57,3 & 0,113 \\
\hline FC55 - CV45 & 652,2 & 27,5 & 85,4 & 57,9 & 0,089 \\
\hline
\end{tabular}

Nota-se que foram atingidas temperaturas bastante elevadas (máximas de 62,5 a $89,9^{\circ} \mathrm{C}$ ), mesmo nos concretos contendo altos teores de cinza volante. Estes resultados contrariam uma informação bastante difundida na literatura: o emprego de pozolanas reduz o calor de hidratação dos concretos [4]-[7]. Tal divergência pode ser explicada pelo fato de geralmente os estudos de elevação de temperatura serem realizados em calorímetros isotérmicos, os quais mantém as amostras a temperaturas constantes (geralmente à $20-25^{\circ} \mathrm{C}$ ). Este ensaio não leva em conta as mudanças de reatividade dos compostos com a alteração da temperatura, consequentemente não refletindo as condições reais de uma estrutura de concreto [1]. Nesta faixa de temperatura, não ocorre a antecipação das reações pozolânicas da cinza volante, sendo o calor gerado pelas mesmas liberado apenas dias depois do início da hidratação do cimento [12]. O uso da calorimetria adiabática, por outro lado, simula as condições reais de uma grande massa de concreto, submetendo as amostras a temperaturas mais elevadas (em geral, $50-90^{\circ} \mathrm{C}$ ). Tais temperaturas antecipam o início das reações pozolânicas para algumas horas após o início da hidratação, somando o calor liberado por ambas as reações [13].

\subsection{Resistência à compressão}

As elevadas temperaturas provenientes da cura adiabática dos concretos podem influenciar de diferentes formas na resistência mecânica dos mesmos. Segundo Neville [32], curas à temperaturas elevadas podem promover uma precipitação não uniforme dos hidratos, uma vez que as reações acontecem de forma muito rápida, não havendo tempo suficiente para que os produtos da hidratação se afastem dos grãos de cimento. Tal fenômeno resultaria na redução da resistência mecânica, sendo reportada por outros autores [33], [34]. Em contrapartida, as elevadas temperaturas poderiam antecipar o início das reações pozolânicas, promovendo a formação adicional de C-S-H [13], [14], além da aceleração da hidratação do próprio cimento Portland [35], [36]. Isso resultaria em ganhos de resistência mecânica nas primeiras idades. Dessa forma, em geral, curas à temperaturas elevadas tendem a aumentar a resistência à compressão nas primeiras idades e reduzir a mesma à longo prazo, em comparação às resistências obtidas em concretos curados à temperatura ambiente. Este comportamento é verificado por Deschner et al. [13], os quais avaliaram o efeito da temperatura (7 - 80 $\left.{ }^{\circ} \mathrm{C}\right)$ na hidratação de pastas de cimento contendo cinza volante. Os autores observaram ganhos de resistência nas primeiras idades, porém perdas em idades mais avançadas com o aumento da temperatura de cura.

A Figura 9 apresenta os resultados de resistência à compressão dos concretos aos 28 dias. Para cada 
mistura, foram rompidos 2 corpos de prova e adotado o valor médio. A barra de erros corresponde à \pm 1 desvio padrão, que variou de 0,1 a 3,7 MPa. Nota-se que, de modo geral, o regime de cura adiabático reduziu as resistências à compressão dos concretros aos 28 dias (reduções da ordem de 10\% em relação aos respectivos concretos curados à $23^{\circ} \mathrm{C}$ ), com exceção da misturas FC35 - CV15. Isso indica que, aos 28 dias, a perda de resistência devido a formação não uniforme dos hidratos foi dominante sobre o ganho de resistência pela antecipação das reações pozolânicas. Na mistura FC35 - CV15, por outro lado, o ganho de resistência resultante da maior formação de C-S-H aparentemente foi maior que a perda de resistência causada pela má formação dos hidratos.

É possível observar uma variabilidade entre as resistências à compressão dos concretos de uma mesma classe de resistência. Vale mencionar que o grande número de misturas preparadas exigiu que fossem usados lotes distintos de cimento: os estudos preliminares para a determinação das curvas de dosagem [22] somados às misturas preparadas para este estudo totalizaram 24 misturas (480 litros de concreto). Ainda que empregados cimentos do mesmo tipo e fabricante, pode ter havido uma ligeira variação das propriedades com a alteração do lote. Ainda, os ensaios foram feitos ao longo de três meses, devido a disponibilidade dos equipamentos e ao grande número de amostras preparadas. Assim, mesmo acondicionando adequadamente o cimento, o mesmo pode ter sofrido variações em suas propriedades ao longo do tempo.

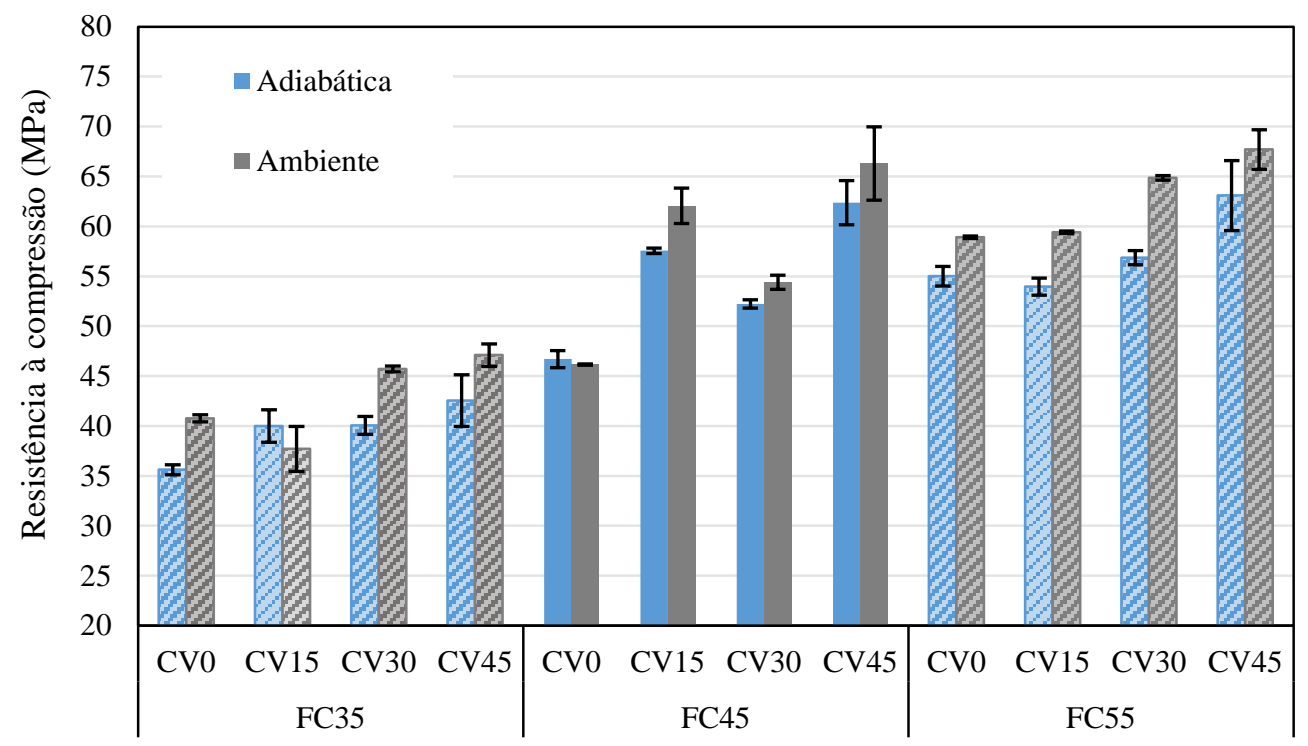

Figura 9: Resistência à compressão dos concretos aos 28 dias.

\subsection{Análise termogravimétrica}

A atividade pozolânica da cinza volante foi avaliada aos 28 dias, em pastas de cimento confeccionadas com as mesmas relações água/aglomerante e teores de substituição de cimento dos concretos, por meio de análise termogravimétrica (TGA). As Figuras 10 a 12 ilustram os resultados da TGA. A perda de massa ocorrida na faixa de 105 a $425^{\circ} \mathrm{C}$, correspondente à água não evaporável, é atribuída à água combinada aos hidratos, enquanto a perda de massa na faixa de $425-550^{\circ} \mathrm{C}$ é atribuída à decomposição do hidróxido de cálcio [4]. 

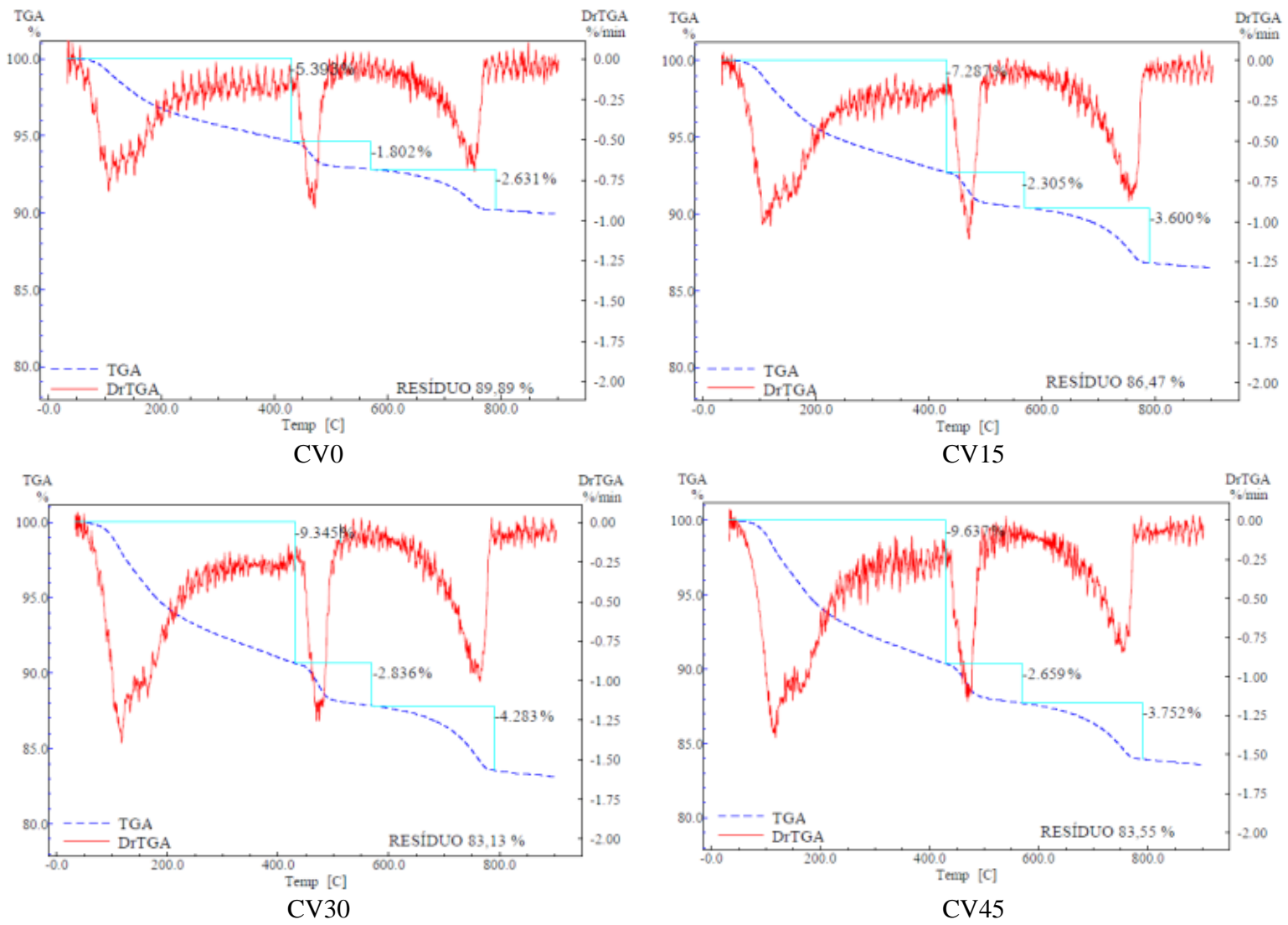

Figura 10: TGA das misturas FC35.
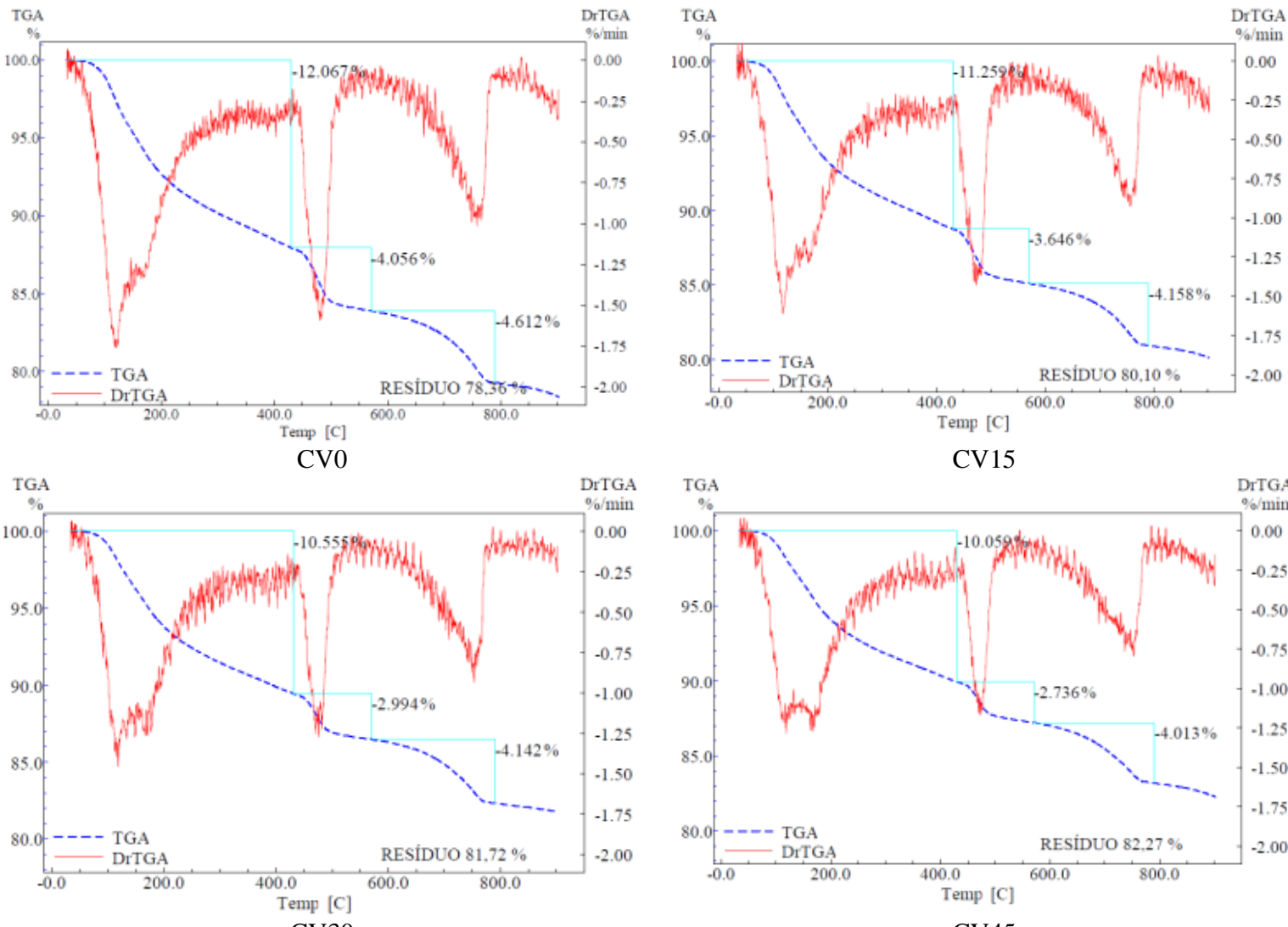

CV15

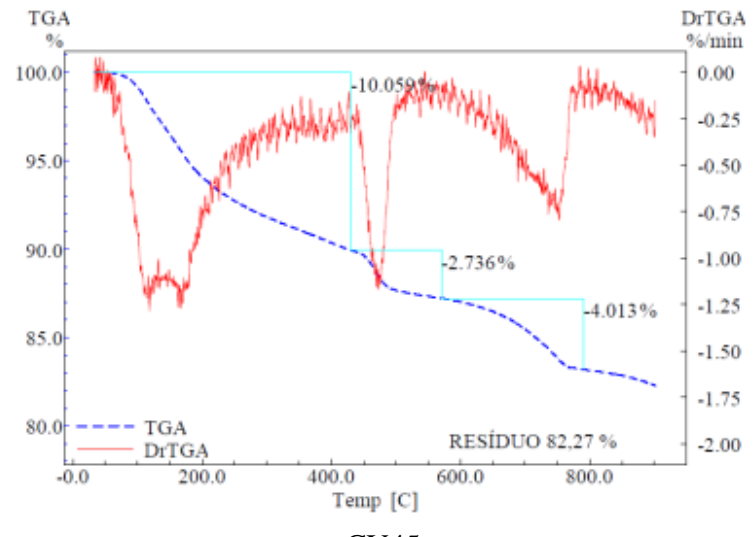

Figura 11: TGA das misturas FC45. 

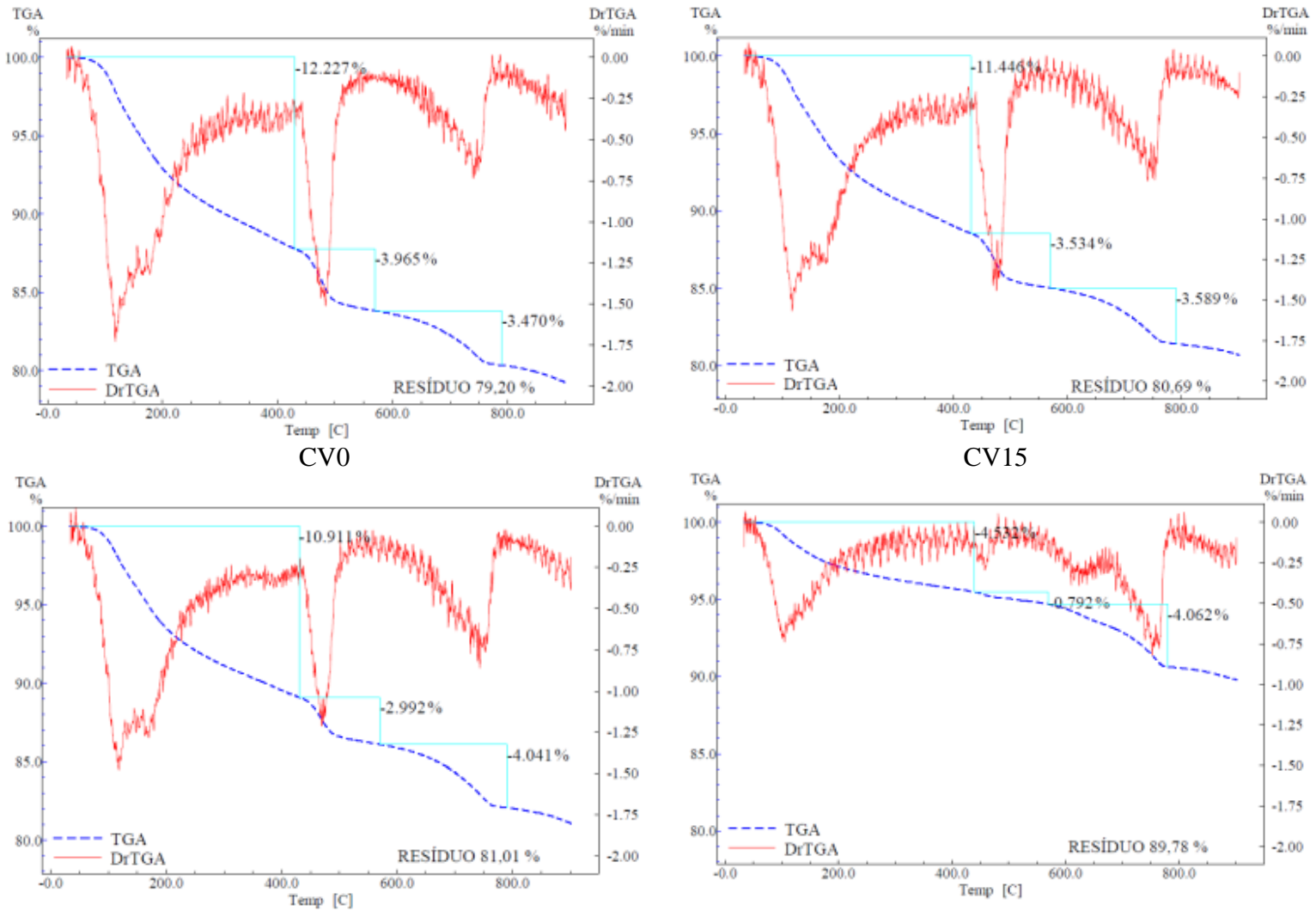

CV15

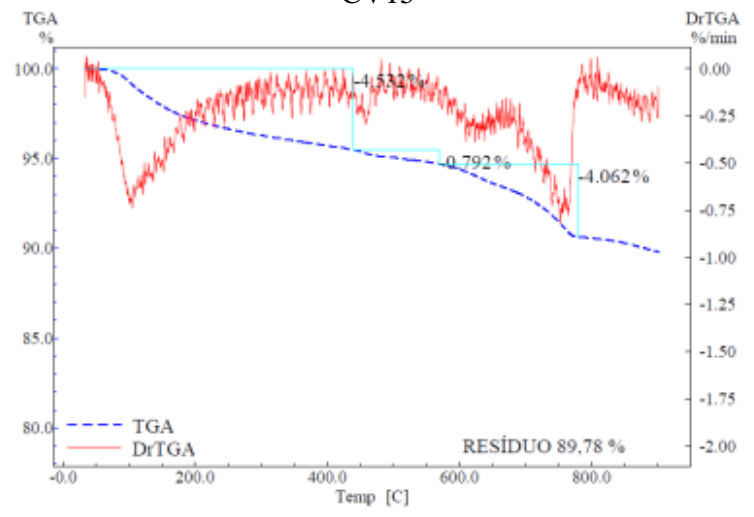

CV30

CV45

Figura 12: TGA das misturas FC55.

A partir das perdas de massa obtidas na TGA, foram calculados os teores de hidratos, $\mathrm{Ca}(\mathrm{OH})_{2} \mathrm{e}$ $\mathrm{CaCO}_{3}$ das amostras, baseado na metodologia proposta por Pilar et al. [37]. Conforme sugerem os autores, as perdas de massa foram corrigidas para a base de não-voláteis. Ainda, foi estimada a carbonatação do $\mathrm{Ca}(\mathrm{OH})_{2}$, corrigindo o teor desta fase. Os resultados estão apresentados na Figura 13. Os valores foram relativizados à massa de cimento das amostras.

Nota-se que, independente da classe de resistência, os teores de $\mathrm{Ca}(\mathrm{OH})_{2}$ aumentaram com o incremento do teor de cinza volante (com exceção da mistura FC55 - CV45). Da mesma forma, a quantidade de hidratos aumentou à medida que o teor de cinza aumentou (novamente, com exceção da mistura FC55 - CV45). Estes resultados são semelhantes aos reportados por Pilar et al. [37]. Segundo os autores, a cinza atuou simultaneamente de duas formas: como pontos de nucleação, melhorando a hidratação do cimento e, consequentemente, aumentando as quantidades de $\mathrm{Ca}(\mathrm{OH})_{2}$ liberado, e como pozolana, resultando na formação adicional de hidratos.

É importante salientar que a água não-evaporável (removida acima de $105^{\circ} \mathrm{C}$ ) é frequentemente utilizada para quantificar a fração hidratada do cimento. Porém, esta medida só dá um indicativo da hidratação, uma vez que parte da água entre as folhas de C-S-H e da estrutura cristalina de AFt e AFm não são quantificadas por esta técnica. Por outro lado, a TGA é um dos melhores métodos conhecidos para a quantificação do hidróxido de cálcio [4]. 


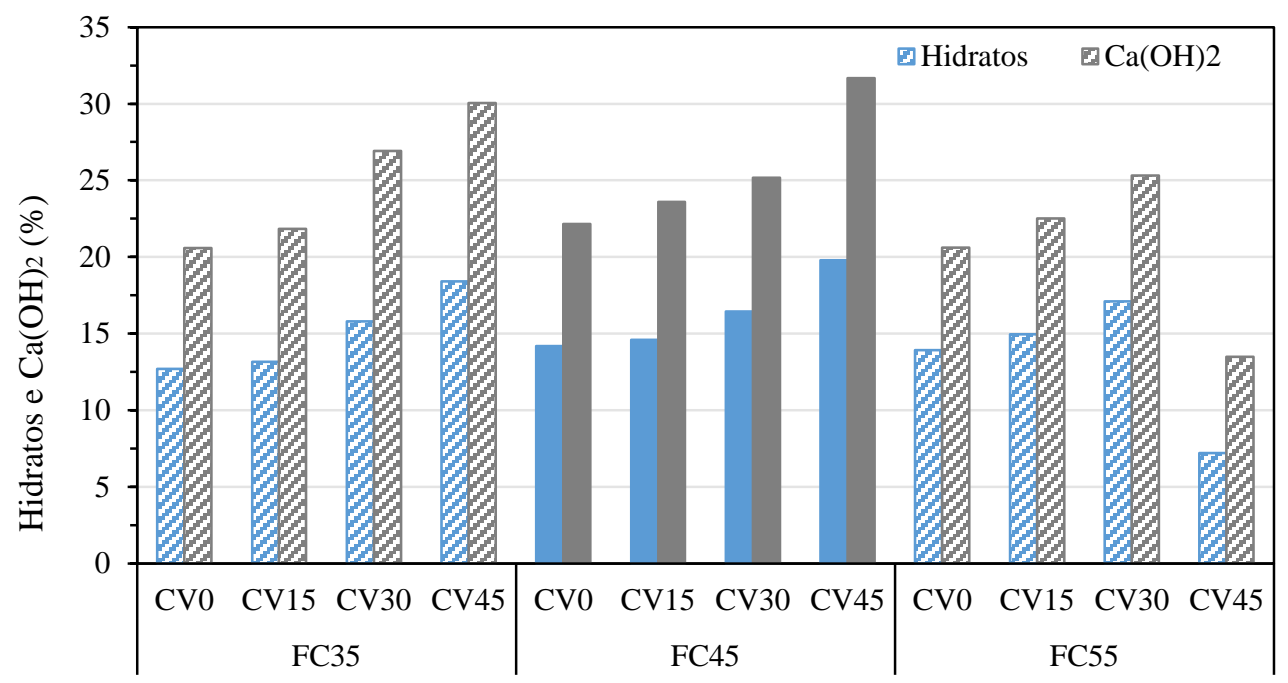

Figura 13: Teores de hidratos e $\mathrm{Ca}(\mathrm{OH})_{2}$ das pastas.

\subsection{Eficácia da cinza volante para uso em grandes massas de concreto}

Apesar dos coeficientes de elevação adiabática de temperatura dos concretos terem sido similares, pode-se observar comportamentos distintos quando avaliada a resistência à compressão juntamente à elevação de temperatura. Para o regime de cura ambiente, as misturas FC45 - CV15 e FC 55 - CV30 apresentaram resistências de aproximadamente $63 \mathrm{MPa}$, enquantos as elevações de temperatura foram respectivamente de $44^{\circ} \mathrm{C}$ e $57^{\circ} \mathrm{C}$. Por sua vez, no regime de cura adiabática, as misturas FC45 - CV30 e FC55 - CV15 apresentaram resistências de aproximadamente $53 \mathrm{MPa}$, porém com respectivas elevações de temperatura de 48 e $54^{\circ} \mathrm{C}$

Dessa forma, para a escolha da melhor composição, dever-se-ia levar em conta simultaneamente a resistência à compressão e elevação de temperatura alcançadas. Para isso, foi determinado um índice de elevação de temperatura por unidade de resistência à compressão (denominado índice de eficiência térmica), dado por ${ }^{\circ} \mathrm{C} / \mathrm{MPa}$. Um menor índice indica que, para uma determinada resistência à compressão, uma menor elevação de temperatura é observada. A Figura 14 ilustra os valores calculados para as resistências à compressão em ambos os regimes de cura.

Nota-se que, a medida que a classe de resistência dos concretos aumentou, o teor de substituição que resultou no menor índice de eficiência térmica também aumentou. Vale salientar que este melhor desempenho é dado principalmente pela contribuição da cinza volante na resistência à compressão, já que a mesma mostrou-se pouco eficiente na redução de temperatura. Tal contribuição na resistência possibilitaria a redução do consumo de aglomerante necessário, consequentemente reduzindo o calor total liberado. A mistura FC45 - CV15, por sua vez, apresentou índices muito inferiores aos demais, devido a resistência à compressão muito acima do esperado. Como já mencionado, o uso de um lote específico de cimento com desempenho superior aos demais é a causa mais provável do fenômeno ocorrido.

Os resultados mostraram que, em alguns casos, o uso de cimento puro ou com baixos teores de cinza volante foi a alternativa mais eficiente simultaneamente do ponto de vista de elevação de temperatura e de resistência à compressão $\left({ }^{\circ} \mathrm{C} / \mathrm{MPa}\right)$. Entretanto, a adoção desta solução potencializaria a ocorrência de etringita tardia caso a temperatura excedesse $70^{\circ} \mathrm{C}$. Mesmo conseguindo-se estimar o ganho de temperatura em função do consumo de aglomerante da mistura, na prática, é difícil garantir que a temperatura máxima do concreto não ultrapasse este limite devido a diversos fatores na execução, que afetam a temperatura de lançamento do concreto: temperatura dos materiais (cimento e agregados), uso de gelo e/ou nitrogênio líquido, temperatura ambiente, etc. Dessa forma, como medida de segurança, poder-se-ia adotar o uso de adições contendo alumina para a mitigação da formação de etringita tardia em concretos submetidos à elevadas temperaturas: segundo Ramlochan et al. [38], cerca de $8 \%$ de metacaulim e $20 \%$ de cinza volante ou escória de alto forno são suficientes para evitar expansão por tal fenômeno.

Por fim, os resultados obtidos são válidos para o conjunto de materiais empregados e podem variar em virtude da composição e da reatividade da cinza e do cimento utilizados. A cinza volante empregada, apesar de ser comercialmente utilizada, apresenta tamanho de partículas relativamente grande (D50 = 58,28 $\mu \mathrm{m})$. O uso de cinzas volantes de finuras mais elevadas poderia contribuir para a redução do índice de eficiência térmica $\left({ }^{\circ} \mathrm{C} / \mathrm{MPa}\right)$ por aumentar a resistência à compressão dos concretos aos 28 dias, sem alterar 
significativamente elevação adiabática de temperatura dos concretos.

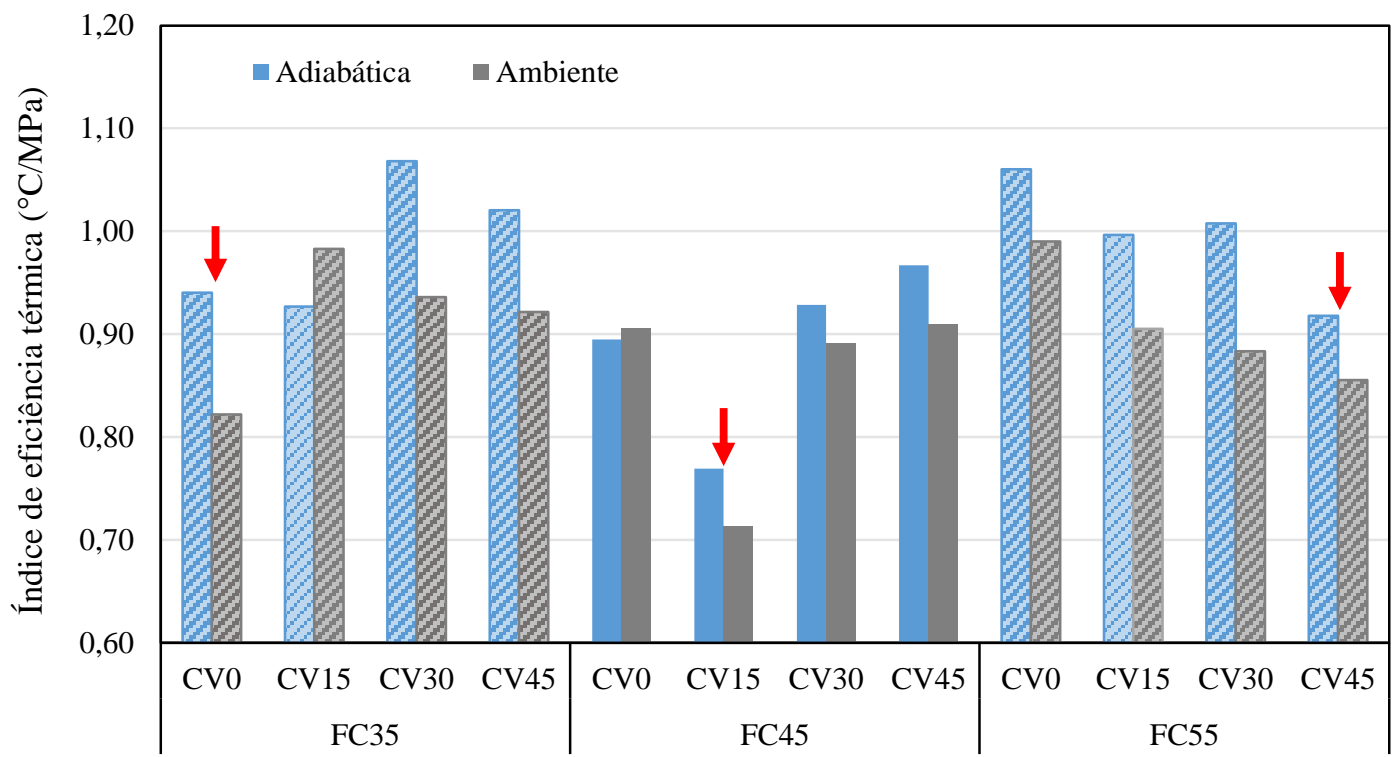

Figura 14: Índice de eficiência térmica dos concretos. As setas indicam as misturas que apresentaram os menores índices de eficiência térmica para cada classe de resistência.

\section{CONCLUSÕES}

Neste trabalho, foram preparados concretos de três classes de resistência à compressão ( 35 , 45 e $55 \mathrm{MPa})$, com $0,15,30$ e $45 \%$ de substituição volumétrica de cimento Portland por cinza volante. A elevação de temperatura dos concretos foi avaliada através de um calorímetro adiabático. Ainda, resistência à compressão dos concretos curados a temperatura ambiente e no regime adiabático foram determinadas aos 28 dias. Por fim, a atividade pozolânica da cinza foi avaliada por meio de análise termogravimetrica. Baseadas nos resultados apresentados neste trabalho, as seguintes conclusões podem ser estabelecidas:

- Independente da classe de resistência e do teor se substituição do cimento pela cinza volante, os coeficientes de elevação adiabática (correspondente à variação de temperatura dividida pelo consumo de aglomerante $/ \mathrm{m}^{3}$ de concreto) foram bastante semelhantes, variando entre 0,110 e $0,128^{\circ} \mathrm{C} \cdot \mathrm{m}^{3} / \mathrm{kg}$.

- $\quad$ O aumento do teor de substituição do cimento pela cinza volante ocasionou o retardo no início da elevação de temperatura dos concretos, com excessão da mistura FC45 - CV45. Nesta mistura, possivelmente o consumo de algomerante muito acima das demais misturas da mesma classe de resistência antecipou o início da liberação de calor.

- $\quad$ O regime de cura adiabático resultou em resistências à compressão aproximadamente $10 \%$ inferiores às dos respectivos concretos curados à temperatura ambiente, aos 28 dias. Tal fato provavelmente ocorreu devido à precipitação não uniforme dos hidratos, uma vez que as reações acontecem de forma muito rápida em consequência das elevadas temperaturas, podendo resultar na redução da resistência mecânica. Este regime, por sua vez, reproduz mais fielmente as condições de cura encontradas na prática, em grandes massas de concreto.

- A análise termogravimétrica apontou a ocorrência de atividade pozolânica pela cinza volante. Os teores de hidróxido de cálcio das misturas foram semelhantes, enquanto houve um aumento na quantidade de hidratos com o aumento do teor de substituição. Isto indica que a presença da cinza volante acelerou a hidração do cimento Portland, havendo maior liberação de hidróxido de cálcio e, ao mesmo tempo, a mesma consumiu parte dele por reação pozolânica, a qual formou maiores quantidade de hidratos.

- $\quad$ O emprego de cinza volante em grandes massas de concreto torna-se uma alternativa pouco eficiente para a redução da liberação de calor. Entretanto, seu uso ainda é indicado para prevenir a formação de etringita tardia. 


\section{AGRADECIMENTOS}

CAPES: Coordenação de Aperfeiçoamento de Pessoal de Nível Superior; NANOTEC: Laboratório de Aplicações de Nanotecnologia em Construção Civil - UFSC, Prof. Dr. Ronaldo Pilar, pelos esclarecimentos e discussões úteis.

\section{BIBLIOGRAFIA}

[1] RILEM, "TCE1: Adiabatic and semi-adiabatic calorimetry to determine the temperature increase in concrete due to hydration heat of the cement", Mater. Struct., v. 30, n. 8, pp. 451-464, 1997.

[2] TAYLOR, H.F.W., FAMY, C., SCRIVENER, K.L. “Delayed ettringite formation”, Cem. Concr. Res., v. 31, n. 5, pp. 683-693, 2001.

[3] ARAÚJO, J.M. “Tensões térmicas em blocos de concreto armado” Teoria e Prática na Eng. Civil., vol. 22, pp. 1-14, 2013.

[4] TAYLOR, H.F.W. “Cement chemistry” Thomas Telford Publ., v. 20, n. 4, p. 335, 1997.

[5] NILI, M., SALEHI, A.M. "Assessing the effectiveness of pozzolans in massive high-strength concrete," Constr. Build. Mater., v. 24, n. 11, pp. 2108-2116, 2010.

[6] ATIŞ, C.D. "Heat evolution of high-volume fly ash concrete”, Cem. Concr. Res., v. 32, n. 5, pp. 751-756, 2002.

[7] LOTHENBACH, B., SCRIVENER, K., HOOTON, D.R. "Supplementary cementitious materials," Cem. Concr. Res., v. 41, n. 12, pp. 1244-1256, 2011.

[8] SALUM, P.L. "Efeito da elevação de temperatura sobre a resistência à compressão de concretos massa com diferentes teores de cinza volante" Dissertação de M. Sc., Universidade Federal de Santa Catarina, SC, Brasil, 2016.

[9] COUTO, D., HELENE, P., ALMEIDA, L.C. "Monitoramento de temperatura em sapata de fundação de grande porte: estudo de caso Parque da Cidade - SP”, IBRACON Structures and Materials Journal, v. 9, n 6, pp. 953 - 968, 2016.

[10] GAMBALE, E.A., TRABOULSI, M.A., FERREIRA, R.B. “Avaliação térmica e tensional do concreto aplicado em Estruturas de Barragens", XXX Seminário Nacional de Grandes Barragens, Foz do Iguaçu, PR, 2015.

[11] SALUM, P. L., GRAEFF, E., MULLER, G. M., et al., "Estudos prévios para execução de bloco de coroamento de grande volume", In: Anais do $56^{\circ}$ Congresso Brasileiro do Concreto - IBRACON, Natal, RN, 2014.

[12] HANEHARA, S., TOMOSAWA, F., KOBAYAKAWA, M., et al., "Effects of water/powder ratio, mixing ratio of fly ash, and curing temperature on pozzolanic reaction of fly ash in cement paste" Cem. Concr. Res., v., 31, n. 1, pp. 31-39, 2001.

[13] DESCHNER, F., LOTHENBACH, B., WINNEFELD, F., et al., "Effect of temperature on the hydration of Portland cement blended with siliceous fly ash”, Cem. Concr. Res., v. 52, pp. 169-181, 2013.

[14] NARMLUK, M., NAWA, T. "Effect of fly ash on the kinetics of Portland cement hydration at different curing temperatures", Cem. Concr. Res., v. 41, n. 6, pp. 579-589, 2011.

[15] KUMAR, M., SINGH, S.K., SINGH, N.P. "Heat evolution during the hydration of Portland cement in the presence of fly ash, calcium hydroxide and super plasticizer”, Thermochim. Acta, v. 548, pp. 27-32, 2012.

[16] HAN, F., LIU, R., WANG, D., et al., "Characteristics of the hydration heat evolution of composite binder at different hydrating temperature”, Thermochim. Acta, v. 586, pp. 52-57, 2014.

[17] HASSAN, K.E., CABRERA, J.G., MALIEHE, R.S. "The effect of mineral admixtures on the properties of high-performance concrete”, Cem. Concr. Compos., v. 22, n. 4, pp. 267-271, 2000.

[18] WANG, X.Y. "Analysis of hydration and strength optimization of cement-fly ash-limestone ternary blended concrete”, Constr. Build. Mater., v. 166, pp. 130-140, 2018.

[19] ABNT NBR 5733, Associação Brasileira de Normas Técnicas, NBR 5733: Cimento Portland de alta resistência inicial. Rio de Janeiro, 1991.

[20] HOPPE FILHO, J., GOBBI, A., PEREIRA, E., et al., "Atividade pozolânica de adições minerais para cimento Portland (Parte I): Índice de atividade pozolânica (IAP) com cal, difração de raios-X (DRX), termogravimetria (TG/DTG) e Chapelle modificado", Revista Matéria, v.22, n.3, 2017. 
[21] ABNT NBR 15895, Associação Brasileira de Normas Técnicas, NBR 15895: Materiais pozolânicos Determinação do teor de hidróxido de cálcio fixado - Método Chapelle modificado. Rio de Janeiro, 2010.

[22] JUNCKES, R. "Influência da adição de cinza volante na elevação de temperatura de concretos aplicados em blocos de fundação", Dissertação de M. Sc., Universidade Federal de Santa Catarina, SC, Brasil, 2015.

[23] ABNT NBR 7212, Associação Brasileira de Normas Técnicas, NBR 7212: Concreto Dosado em Central. Rio de Janeiro, 2012.

[24] DESCHNER, F., WINNEFELD, F., LOTHENBACH, B., et al., "Hydration of Portland cement with high replacement by siliceous fly ash”, Cem. Concr. Res., v. 42, n. 10, pp. 1389-1400, 2012.

[25] TANG, S.W., CAI, X.H., HE, Z., et al., "Hydration process of fly ash blended cement pastes by impedance measurement", Constr. Build. Mater., v. 113, pp. 939-950, 2016.

[26] MOON, G.D., OH, S., CHOI, Y.C. "Effects of the physicochemical properties of fly ash on the compressive strength of high-volume fly ash mortar", Constr. Build. Mater., v. 124, pp. 1072-1080, 2016.

[27] DE LA VARGA, I., CASTRO, J., BENTZ, D.P., et al., "Evaluating the hydration of high volume fly ash mixtures using chemically inert fillers", Constr. Build. Mater., v. 161, pp. 221-228, 2018.

[28] NICOLEAU, L., SCHREINER, E., NONAT, A. "Ion-specific effects influencing the dissolution of tricalcium silicate”, Cem. Concr. Res., v. 59, pp. 118-138, 2014.

[29] SCHÖLER, A., LOTHENBACH, B., WINNEFELD, F., et al., "Early hydration of SCM-blended Portland cements: A pore solution and isothermal calorimetry study", Cem. Concr. Res., v. 93, pp. 71-82, 2017.

[30] FURNAS "Concretos massa, estrutural, projetado e compactado com rolo - Ensaios e propriedades", $1^{\mathrm{a}}$ ed., São Paulo: PINI, 1997.

[31] THOMAS, M. "Supplementary Cementing Materials in Concrete", 1st ed. Boca Raton: Taylor e Francis Group, 2013.

[32] NEVILLE, A.M. "Properties of Concrete", 5th ed. Pearson, 2011.

[33] ALDEA, CM., YOUNG, F., WANG, K., et al., "Effects of curing conditions on properties of concrete using slag replacement", Cem. Concr. Res., v. 30, pp. 465-472, 2000.

[34] TURUALLO, G., SOUTSOS, M.N. "Supplementary cementitious materials: Strengh development of self-compacting concrete under diferente curing temperature", In: $5^{\text {TH }}$ International conference of Euro Asia Civil Engineering Forum, pp.699 - 704, 2015.

[35] LOTHENBACH, B., WINNEFELD, F., ALDER, C., et al., "Effect of temperature on the pore solution, microstructure and hydration products of Portland cement pastes", Cem. Concr. Res., v. 37, pp. 483-491, 2007.

[36] LOTHENBACH, B., MATSCHEI, T., MÖSCHNER, G., et al., "Thermodynamic modelling of the effect of temperature on the hydration and porosity of Portland cement", Cem. Concr. Res., v. 38, pp. 1-18, 2008.

[37] PILAR, R., SCHANKOSKI, R.A., MORO, A.J., et al., "Avaliação de pastas de cimento Portland contendo cinza pesada moída" Revista Matéria, v. 21, n. 1, pp. 92-104, 2016.

[38] RAMLOCHAN, T., ZACARIAS, P., THOMAS, M.D.A., et al., "The effect of pozzolans and slag on the expansion of mortars cured at elevated temperature Part I: Expansive behaviour", Cem. Concr. Res., v. 33, no. 8, pp. 807-814, 2003.

\section{ORCID}

Paulo Ricardo de Matos

Ricardo Junckes

Luiz Roberto Prudêncio Jr. https://orcid.org/0000-0002-3695-1356

https://orcid.org/0000-0003-2187-3604

https://orcid.org/0000-0002-7594-7077 